\title{
Round goby versus marbled crayfish: alien invasive predators and competitors
}

\author{
Sara Roje ${ }^{1, *}$, Luise Richter ${ }^{2}$, Susanne Worischka ${ }^{2,3}$, Marek Let ${ }^{1}$, Lukáš Veselý ${ }^{1}$ and Miloš Buřič ${ }^{1}$ \\ ${ }^{1}$ University of South Bohemia in České Budějovice, Faculty of Fisheries and Protection of Waters, South Bohemian Research Center \\ of Aquaculture and Biodiversity of Hydrocenoses, Zátiší 728/II, 38925 Vodňany, Czech Republic \\ ${ }^{2}$ Institute of Hydrobiology, Technische Universität Dresden, Dresden, 01062 Dresden, Germany \\ ${ }^{3}$ Institute of Integrated Natural Sciences, University Koblenz-Landau, Universitätsstrasse 1, 56070 Koblenz, Germany
}

Received: 29 January 2021 / Accepted: 24 April 2021

\begin{abstract}
Aquatic biodiversity is threatened by spread of invasive alien species. Round goby Neogobius melanostomus is an invasive fish in large European rivers as well as in coastal waters near their mouths and marbled crayfish Procambarus virginalis is a highly invasive crustacean. Both are small, bottom-dwelling species occupying similar habitat and shelters and utilizing similar food sources. We hypothesized that goby presents a threat to both native and non-native astacofauna in invaded ecosystems. We tested this through laboratory experiments designed to determine aggressiveness and competitiveness of goby against marbled crayfish as a model for other North American cambarid crayfish, assessing goby prey size selection and competition with marbled crayfish for space and shelter. Gobies showed high aggressiveness and dominance over the crayfish. Goby predation on juvenile crayfish was limited by mouth gape size. In goby/crayfish pairs of similar weight, gobies were more aggressive, although each affected the behavior of the other.
\end{abstract}

Keywords: Biological invasion / freshwater / predation / shelter competition / species interaction

\begin{abstract}
Résumé - Le gobie à tache noire versus l'écrevisse marbrée: des espèces exotiques envahissantes prédatrices et concurrentes. La biodiversité aquatique est menacée par la propagation d'espèces exotiques envahissantes. Le gobie à taches noires Neogobius melanostomus est un poisson envahissant dans les grands fleuves européens ainsi que dans les eaux côtières près de leur embouchure et l'écrevisse marbrée Procambarus virginalis est un crustacé très envahissant. Toutes deux sont de petites espèces vivant sur le fond, occupant des habitats et des abris similaires et utilisant des sources de nourriture similaires. Nous avons émis l'hypothèse que le gobie constitue une menace pour l'astacofaune indigène et non indigène dans les écosystèmes envahis. Nous avons testé cette hypothèse par le biais d'expériences en laboratoire conçues pour déterminer l'agressivité et la compétitivité du gobie contre l'écrevisse marbrée comme modèle pour les autres écrevisses cambarides d'Amérique du Nord, en évaluant la sélection de la taille des proies du gobie et la compétition avec l'écrevisse marbrée pour l'espace et les abris. Les gobies ont montré une grande agressivité et une forte dominance sur les écrevisses. La prédation des gobies sur les écrevisses juvéniles était limitée par la taille de l'ouverture de la bouche. Dans les paires gobie/écrevisse de poids similaire, les gobies étaient plus agressifs, bien que chacun ait affecté le comportement de l'autre.
\end{abstract}

Mots clés : Invasion biologique / eau douce / prédation / compétition pour l'abri / interaction des espèces

\section{Introduction}

Fish and crayfish have multiple relationships and portraying them solely as prey or predator can be misleading. In aquatic habitats, both groups often represent keystone species, and their competition for resources can have high impact

\footnotetext{
*Corresponding author: sroje@frov.jcu.cz
}

(Bond, 1994; Crandall and Buhay, 2008). Although the ranges of some non-native fish overlap with those of non-native crayfish, with the exception of information with respect to aggressive encounters, little is known about interactions between invasive benthic fish and native and invasive crayfish, although they co-exist and use similar niches and substrates as shelter (Church et al., 2017). Filling the knowledge gaps is worthwhile, because both fish and decapods may regulate community biodiversity through their longevity and trophic 
S. Roje et al: Knowl. Manag. Aquat. Ecosyst. 2021, 422, 18

Table 1. Biometric data of marbled crayfish size groups used in experiment on round goby predation on crayfish (Experiments 1-3). Data are presented as mean \pm standard deviation (SD) and range.

\begin{tabular}{|c|c|c|c|c|c|}
\hline Exp. & Size class & Weight (mg) & Total length (mm) & Carapace length (mm) & Carapace height $(\mathrm{mm})$ \\
\hline \multirow{3}{*}{1,2} & Small & $15.2 \pm 4.0(10-25)$ & $10 \pm 1.4(8-12)$ & $4.7 \pm 0.9(3-6)$ & $2.3 \pm 0.5(2-3)$ \\
\hline & Medium & $58.6 \pm 12.7(40-80)$ & $15.3 \pm 0.5(15-16)$ & $7.3 \pm 0.6(6-8)$ & $3.7 \pm 0.8(3-5)$ \\
\hline & Large & $210.6 \pm 60.3(100-300)$ & $22.8 \pm 1.7(21-25)$ & $11 \pm 0.6(10-12)$ & $5.7 \pm 0.8(5-7)$ \\
\hline \multirow[b]{2}{*}{3} & Small juveniles & $5.7 \pm 0.6(5.1-7)$ & $7.1 \pm 0.4(6.5-8)$ & $3.9 \pm 0.4(3-4.5)$ & - \\
\hline & Medium juveniles & $13.8 \pm 4.8(9-22)$ & $10 \pm 1.4(8-12)$ & $4.7 \pm 0.9(3-6)$ & $2.3 \pm 0.5(2-3)$ \\
\hline
\end{tabular}

specialization (Reynolds, 2011). Alien predatory fishes can negatively impact native crayfishes, while fish populations may be affected by predation and competition from multiple organisms, including exotic crayfish (Degerman et al., 2007).

Round goby Neogobius melanostomus (Pallas, 1814) is an alien invasive species from the Eurasian Ponto-Caspian region that presents high potential for competition with native species (Jude, 1997; Borcherding et al., 2011; Brandner et al., 2013). The species has invaded, or expanded its range in, large European rivers including the Danube (Vanderploeg et al., 2002), Rhine (Van Kessel et al., 2009), Vistula (Grabowska et al., 2008), and Volga (Copp et al., 2005) and has established invasive populations in North America (Kornis et al., 2013). A primary characteristic is its formation of vital and dense populations with rapid spread both upstream and downstream (Roche et al., 2015; Verliin et al., 2017). Round goby is an adaptable generalist benthic feeder with a broad diet spectrum including zooplankton, benthic invertebrates, and fish eggs and larvae (Kornis et al., 2012). Small benthic fish like round goby can feed on small juvenile crayfish as well as exploit the same food sources and be subject to the same predators as larger crayfish (Dorn and Mittelbach, 1999).

The marbled crayfish Procambarus virginalis (Lyko, 2017) is a unique invasive crayfish that reproduces parthenogenetically and has been included in the list of European Union invasive species of concern since August 2016 (EU regulation No. 1143/2014 and Commission Implementing Regulation No. 2016/1141). The marbled crayfish has been reported established in many European countries and on other continents (Chucholl and Pfeiffer, 2010; Lipták et al., 2016; Hossain et al., 2018; Andriantsoa et al., 2019). It is omnivorous, feeding on algae, detritus, zoobenthos, and macrophytes. It can become abundant and form high-density populations in a short time (Lipták et al., 2019). As Procambarus fallax (Hagen, 1870) is a crayfish endemic to Florida and closest relative to the parthenogenetic $P$. virginalis, we used marbled crayfish as a representative of other successful invasive members of the Cambaridae originally from North America (Kouba et al., 2014; Patoka et al., 2016).

Direct interactions between fish and crayfish include predation and competition for shelter. When co-existing fish and decapods are omnivores, there will be competition and mutual predation, depending on relative size and vulnerability (Reynolds, 2011). Bottom-dwelling fish such as round goby can potentially exert negative effects on crayfish in addition to predation, as they use similar food sources and compete for shelter (Gebauer et al., 2019). Limited shelter availability can increase the vulnerability to predation of the weaker opponent (Church et al., 2017).

We hypothesized that (a) round goby represents a predatory threat to smaller crayfish (tested in experiments 1 , 2 and 3 in multiple scenarios), (b) this predatory impact and food selection is depending on marbled crayfish sizes available, and (c) round goby is more aggressive and dominates over larger crayfish in competition for shelter (experiments 4 and 5). The goal of the present study was to determine the effect of round goby predation, aggressiveness, and shelter dominance on crayfish under laboratory conditions, using the marbled crayfish as a model for other invasive species.

\section{Materials and methods}

Round goby (TL $63.54 \pm 7.6 \mathrm{~mm}$ ) were collected from the River Elbe in September 2018 (Ústí and Labem, north of Czech Republic) using a battery powered backpack electrofishing unit (FEG 1500, EFKO, Leutkirch, Germany) while experiments were carried out during November and December 2018. Fish were transferred to the experimental facility of the Research Institute of Fish Culture and Hydrobiology in Vodňany, University of South Bohemia in České Budějovice and held in troughs embedded in a small recirculating system for acclimatization to laboratory conditions. Troughs were filled with aged tap water and cleaned every second day. Fish were fed ad libitum with frozen chironomid larvae daily.

Marbled crayfish were obtained from our own culture and fed ad libitum on chironomid larvae and carrot daily. Continuous culture enabled the use of all developmental stages in this research.

Animals were weighed using a digital precision balance (Kern 572-35, Kern and Sohn, Germany) to the nearest $0.5 \mathrm{mg}$. Crayfish total length (TL, from tip of the rostrum to the posterior median edge of telson), carapace length (CL, from tip of the rostrum to the posterior median edge of the cephalothorax) and carapace height $(\mathrm{CH})$ were measured with Vernier calipers, and fish TL (from the tip of the snout to the tip of the tail) was measured with a ruler to the nearest $1 \mathrm{~mm}$. All crayfish individuals were measured (TL, CL, CH) before performing the following experiments $(1,2$, and 3$)$ thus separated according to their weight (small, medium, large, small juveniles, medium juveniles) in five different aquariums that later could be used for the experiments (Tab. 1), same as for following experiments (4 and 5) weight-matched pairs of 
S. Roje et al: Knowl. Manag. Aquat. Ecosyst. 2021, 422, 18

Table 2. Biometric data of marbled crayfish and round goby used in experiments on competition for shelter (Experiments 4-5). Data are presented as mean \pm standard deviation (SD) and range.

\begin{tabular}{lllr}
\hline Exp. & Animal & Weight $(\mathrm{mg})$ & Total length (mm) \\
\hline & Marbled crayfish & $116.9 \pm 27.5(60-180)$ & $32.52 \pm 14.8(31-44)$ \\
& Round goby & $123.5 \pm 32.1(60-190)$ & $44.7 \pm 11.29(38-53)$ \\
5 & Marbled crayfish & $255 \pm 10.4(200-500)$ & $20.61 \pm 2.72(16-25)$ \\
& Round goby & $272 \pm 95.8(200-500)$ & $57.27 \pm 4.02(52-65)$ \\
\hline
\end{tabular}

round goby and crayfish for each experiment were selected and separated before (Tab. 2).

Animals appeared healthy and active and were used only once for each experiment to avoid any learning effect during the experiments. Crayfish with missing or regenerating chelae or showing signs of approaching molt or not fully hardened following molting were omitted from experiments. No specific permissions were required for the location in this study. All facilities used for housing of experimental animals and for experimental procedures were located indoors in separate units with no direct connection to surface waters and were protected against the escape of any organisms used.

\subsection{Goby predation on crayfish}

\subsubsection{Experiment 1, single size predation}

Thirty round gobies (TL $74.2 \pm 7.25 \mathrm{~mm}$ ) were placed in separate $27 \mathrm{~L} \times 19 \mathrm{~W} \times 7.5 \mathrm{H} \mathrm{cm}$ plastic boxes containing 21 aged tap water and $150 \mathrm{~cm}^{3}$ of fine sand for acclimatization and starvation. Water temperature was set at $21^{\circ} \mathrm{C}$ and the light regime to 12:12 h light: dark. After $24 \mathrm{~h}$, water was exchanged, and one crayfish was randomly added to each of 30 boxes containing one round goby.

We selected three size classes of crayfish: small (10-25 mg), medium (40-80 mg) and large (100-300 mg) (Tab. 1) with 10 replicates of each size class to assess round goby ability to swallow crayfish of various sizes.

After $24 \mathrm{~h}$ we evaluated crayfish type of response with paired goby and we noted if crayfish was consumed, killed and partially consumed or still alive. Following the experiment, we measured round goby total length (TL) and the smallest internal dimension of the fish mouth (here referred as mouth gape) was measured using a set of conical plastic tips consisting of a plastic body with different measurement head attachments. The plastic tip was inserted into the fish mouth until a marked resistance was reached (Supplement 2). In this position, mouth gape size could be determined from fine gradients of the plastic tip to the nearest $0.01 \mathrm{~mm}$.

\subsubsection{Experiment 2, choice-size predation}

Following exp. 1., we increased crayfish number, so we stocked one round goby (TL $78.0 \pm 7.85 \mathrm{~mm}$ ) and three juvenile crayfish from each size class in $65 \mathrm{~L} \times 50 \mathrm{~W} \mathrm{~cm}$ elliptical arenas with $650 \mathrm{~cm}^{3}$ of sand and 101 water (water level $5 \mathrm{~cm}$ ). One half of each arena was shaded by an opaque cover to reduce stress during the light period $(12: 12 \mathrm{~h}$ light: dark). The experiment was conducted at $17^{\circ} \mathrm{C}$ and at $21^{\circ} \mathrm{C}$ (the higher temperature according to prevailing summer water temperatures of River Elbe and the lower one to its slightly colder tributaries). At each temperature, we carried out 18 replicates plus 7 control replicates in which crayfish were stocked without round goby to assess possible cannibalism. At 24 hours post-stocking, we counted the number of crayfish of each size class consumed by round goby and analyzed the association of round goby mouth gape and water temperature on consumption rate and size selection.

\subsubsection{Experiment 3, biomass consumption}

In the third experiment, single round goby (TL $76.3 \pm 3.06 \mathrm{~mm}$ ) were placed in the experimental elliptical arenas under the same light regime as in the size-choice experiment along with 50 small juveniles or 50 medium juvenile crayfish (Tab. 1). Water temperature was $17^{\circ} \mathrm{C}$. Four replicates were conducted with each class size. After 24 hours, we counted remaining crayfish and measured the weight of surviving and unconsumed crayfish to calculate the biomass consumed per 24 hours.

\subsection{Competition for shelter}

\subsubsection{Experiment 4, daily observations of competition for shelter over 8 days}

The experiment was conducted in aquaria $(40 \mathrm{~L} \times 20 \mathrm{~W} \times$ $25 \mathrm{H} \mathrm{cm})$ with a layer of sand $\left(1500 \mathrm{~cm}^{3}\right)$ and 71 aged tap water aerated by a single air stone placed in a corner and equipped with a single shelter situated in the middle of the shorter side of the aquarium (half of a ceramic flowerpot, entry diameter: $4.7 \mathrm{~cm}$, height: $4 \mathrm{~cm}$, length $4.5 \mathrm{~cm}$ ). Round goby and marbled crayfish were weighed to form weight-matched pairs with wet weight difference $<5 \%$ (Tab. 2). Prior to the experiment, goby and marbled crayfish were placed separately in $27 \mathrm{~L} \times 19 \mathrm{~W}$ $\times 7.5 \mathrm{H} \mathrm{cm}$ plastic boxes with $150 \mathrm{~cm}^{3}$ sand and 21 water for 24 hours to standardize the starvation level. The light regime was $12: 12 \mathrm{~h}$ light: dark and water temperature $\sim 20^{\circ} \mathrm{C}$. The weight-matched pairs were placed simultaneously in each aquarium (20 replications) and observed for the following 8 days. Visual observations of all twenty weight-matched pairs were made only during daylight hours at 08.00, 11.00, 14.00, and 17.00 o'clock for total of 8 days. Animals did not receive supplemental food during the course of the experiment. The position of all individuals was described to record whether an animal was in the shelter, in the proximity of the shelter (near to entry or beside the shelter), hidden in the sand, in a corner, in the corner with the air stone, or active in other areas of the bottom. Mortality and molting events in crayfish were recorded. 


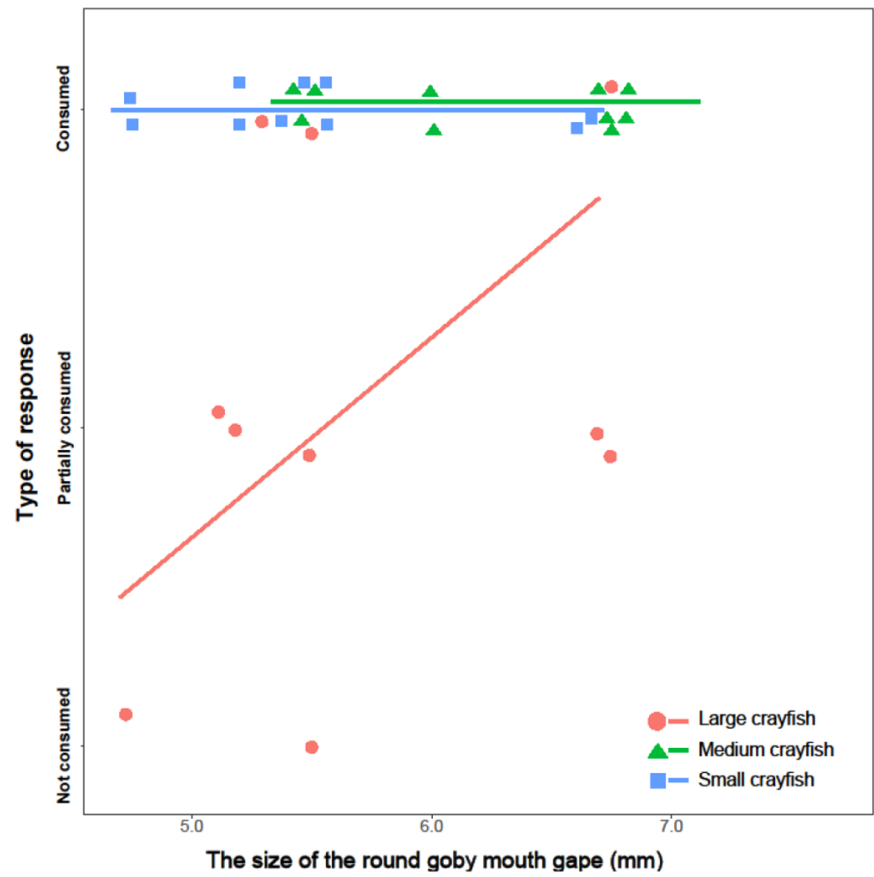

Fig. 1. Relationship of round goby Neogobius melanostomus mouth gape and marbled crayfish Procambarus virginalis size classes consumed over $24 \mathrm{~h}$.

\subsubsection{Experiment 5, twenty-four-hour observation of competition for shelter}

We used similar conditions as for the eight-day experiment but with the air stone removed to omit recording disturbance in the experiment of continuous observation for 24 hours. Another 16 pairs of round goby and marbled crayfish were weight-matched (Tab. 2) and acclimated as described in previous experiment. Inter-specific pairs were stocked in aquaria and video-recorded. We conducted 16 replicates. Animal activity was recorded as aggressive interaction (attack, biting, pursuit), time spent in shelter, and avoidance (retreat from opponent prior to attack) (Tabs. 4 and 5), detailed and carefully analyzed by eye. Duration of attack was recorded as the time from the first aggressive act to cessation of interaction (Tab. 5). At the conclusion of the experiment, we measured round goby/marbled crayfish length and weight and assessed injuries.

\subsection{Data analysis}

Since many data sets did not meet the assumptions for parametric tests, even after transformation, nonparametric tests were used. For experiment 1, we used Firth's bias-reduced penalized-likelihood logistic regression to analyze the type of response between marbled crayfish (which was taken as a factor and assessed as: $0=$ not consumed, $0.5=$ killed and partially consumed, $1=$ consumed) and relationship with round goby mouth gape and total length. The simple linear regression between round goby mouth gape and round goby total length was evaluated. In experiment 2 , a generalized linear model (hereafter, GLM) with an assumed quasi-binomial distribution, that accounts for data underdispersion, was used to analyze the

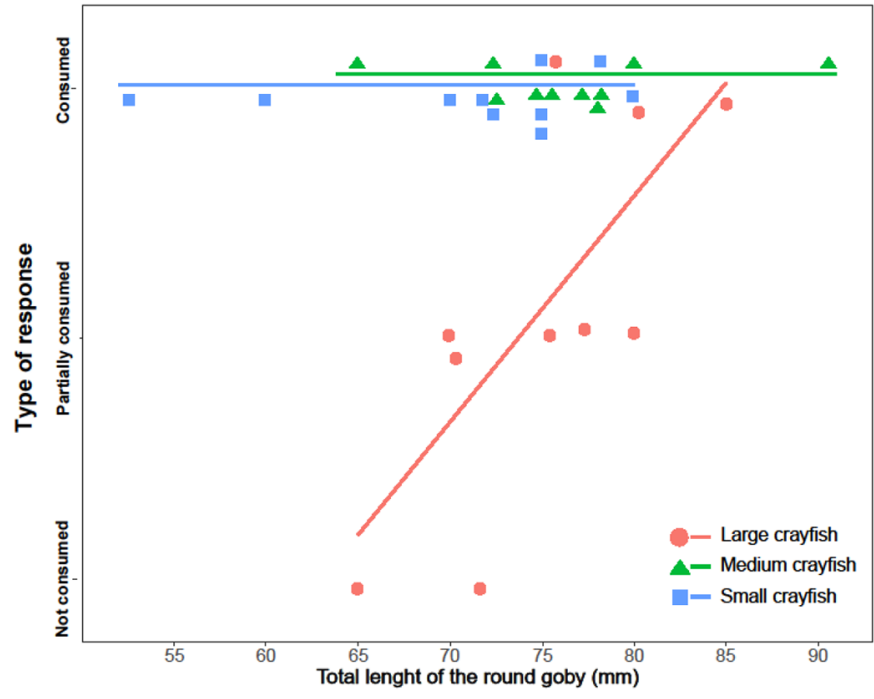

Fig. 2. Relationship of round goby Neogobius melanostomus total length and marbled crayfish Procambarus virginalis size classes consumed over $24 \mathrm{~h}$.

quantity of three crayfish size categories consumed and their relationship with round goby mouth gape under two different temperatures. Also, linear relationship between round goby mouth gape and crayfish size class under two temperatures was calculated. For experiment 3, we performed a test using GLM with quasi-binomial distribution, that accounts for data overdispersion, to assess the difference in wet mass of two offered crayfish size groups consumed by round goby. For experiment 4, we used GLM with Poisson distribution. As post-hoc testing was not possible for Poisson distribution errors, results are based on predictions and estimations. We used detailed data from visual observations to better understand interactions of round goby and marbled crayfish over the course of 24 hours. For experiment 5 we performed GLM with Gaussian distribution to analyze the difference in time spent in shelters and to test the number of attacks per animal during the light and dark periods. Analysis was conducted with R software and package ggplot 2 was used for data visualization (R Development Core Team, v. 4.0.3., 2020). In the case of Figures 1-3 points are dispersed within 3 or more lines of the y-axis because of a jitter-like function enabling to visualize individual points without their coverage.

\section{Results}

\subsection{Round goby predation on crayfish}

\subsubsection{Experiment 1, single size predation}

Mean round goby mouth gape (diameter) was $5.7 \pm 0.74$ (4.7-7.7) $\mathrm{mm}$. The type of response of crayfish due to round goby predation (which was taken as a factor and assessed as: $0=$ not consumed, $0.5=$ killed and partially consumed, $1=$ consumed) did differ significantly between size groups (likelihood ratio test $=16.49 ; \mathrm{df}=5 ; p=0.005)$. The type of response of all size classes of marbled crayfish was correlated with mouth gape and total length of round goby individuals $(p=0.005)$, indicating that round goby was not able to 


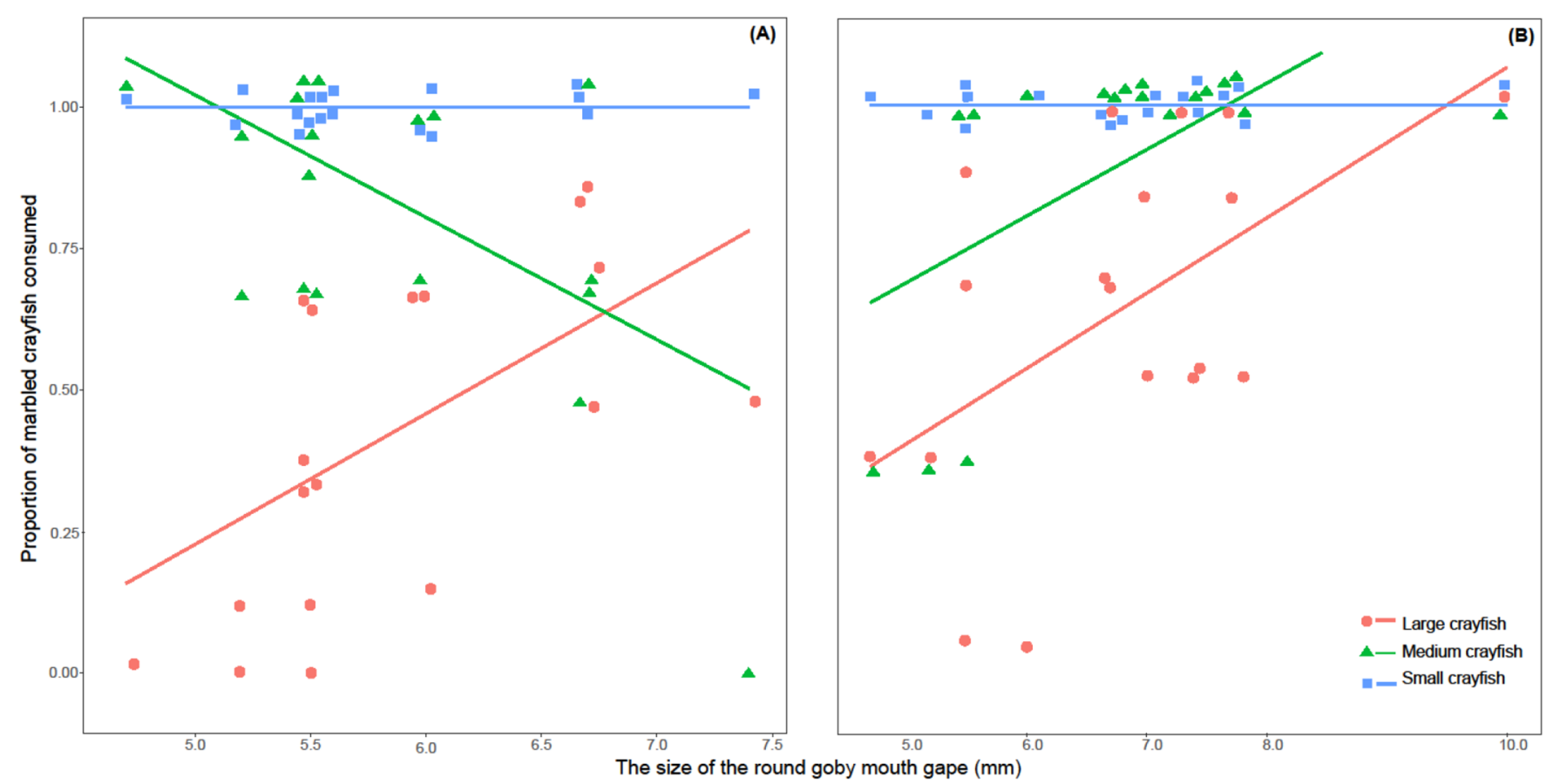

Fig. 3. Relationship of mouth gape of round goby Neogobius melanostomus and the proportion of consumed marbled crayfish Procambarus virginalis of 3 size classes at $17^{\circ} \mathrm{C}(\mathrm{A})$ and $21^{\circ} \mathrm{C}(\mathrm{B})$.

Table 3. Linear relationships between round goby mouth gape and crayfish class size under two temperatures. Negative effect ( - ), positive effect $(+)$, no effect $(0), n=18$.

\begin{tabular}{lllll}
\hline Crayfish size class & \multicolumn{2}{c}{ Temperature $17^{\circ} \mathrm{C}$} & \multicolumn{2}{c}{ Temperature $21^{\circ} \mathrm{C}$} \\
\cline { 2 - 4 } & $p$-value & $R^{2}$ & $p$-value & $0.621(0)$ \\
Small & $0.764(0)$ & 0.480 & $0.008(+)$ & 0.322 \\
Medium & $0.003(-)$ & 0.308 & $0.018(+)$ & 0.257 \\
Large & $0.005(+)$ & 0.281 & 0.42 \\
\hline
\end{tabular}

consume all provided prey size classes. Due to the significant linear relationship between round goby mouth gape and total length (Supplement 1) we used mouth gape size in further analysis as confounding factor as it is more directly causing the limitation of predation than total length.

Generally, all small and all medium crayfish were consumed (Figs. 1 and 2), while $70 \%$ of large crayfish were killed and partially consumed with parts of crayfish found in the experimental arena.

\subsubsection{Experiment 2, choice-size predation}

Mean mouth gape (diameter) of round goby was $6.2 \pm 1.1$ (4.7-10) $\mathrm{mm}$. We found a significant relationship among size of the round goby mouth gape and crayfish size class consumption under two different water temperatures $\left(F_{[2,111]}=\right.$ $17.54, p<0.0001)$. At $17^{\circ} \mathrm{C}$ all small crayfish were eaten in $24 \mathrm{~h}$, with a slightly less number of medium crayfish consumed and few large-sized eaten (Fig. 3). With increasing gape size, round gobies consumed more crayfish of the larger size class, while the number of medium-sized crayfish eaten was negatively correlated with mouth gape (Tab. 3). At $21^{\circ} \mathrm{C}$, all small crayfish were eaten, and the number of consumed crayfish increased compared to $17^{\circ} \mathrm{C}$ (Fig. 3). At $21^{\circ} \mathrm{C}$, a positive correlation of mouth gape with the quantity of crayfish of all size classes eaten was observed (Fig. 3, Tab. 3). In general, with an increase of temperature and gape size, predation on crayfish increased. As all small crayfish were consumed at both temperatures, total biomass consumed was $45.6 \mathrm{mg}$. Average biomass of medium eaten crayfish at $17^{\circ} \mathrm{C}$ was $89.29 \mathrm{mg}$, and at $21^{\circ} \mathrm{C}$ was much higher at $156.2 \mathrm{mg}$. Average biomass of large crayfish eaten was $258.6 \mathrm{mg}$ at $17^{\circ} \mathrm{C}$ and $391.95 \mathrm{mg}$ at $21^{\circ} \mathrm{C}$.

\subsubsection{Experiment 3, biomass consumption}

Mean mouth gape (diameter) of round goby was $5.1 \pm 0.34$ (4.5-5.5) $\mathrm{mm}$. We found a significant relationship in the number of the two juvenile crayfish classes preyed by round goby $\left(F_{[1,6]}=11.73, p=0.01\right)$. There was a significant relationship in the amount of consumption of small 


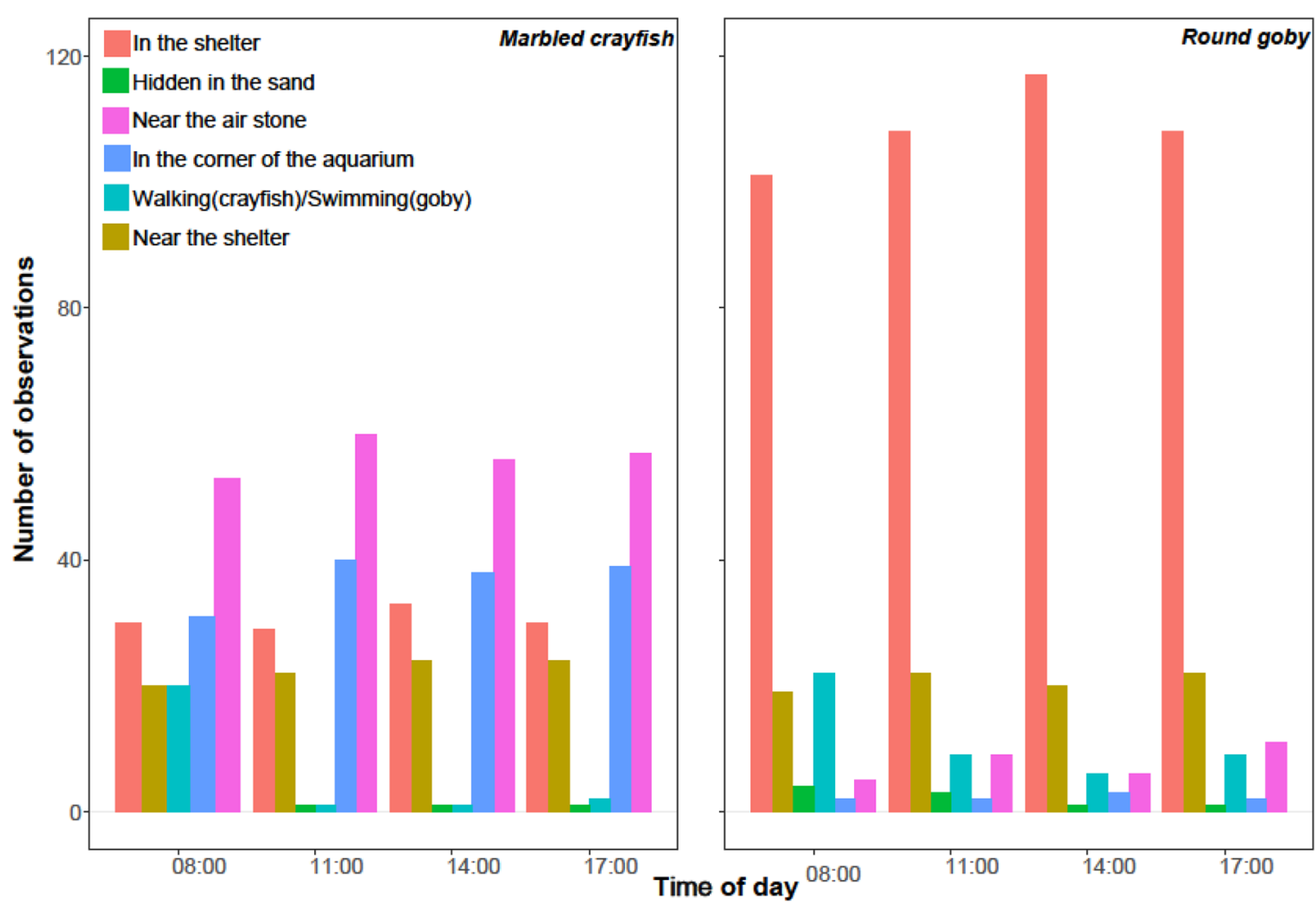

Fig. 4. Number of observations of round goby Neogobius melanostomus and marbled crayfish Procambarus virginalis at specific locations in the experimental arena with respect to time $(08: 00,11: 00,14: 00$, and 17:00).

$(5.7 \pm 0.63 \mathrm{mg}, \mathrm{n}=10)$ and medium $(13.8 \pm 4.82 \mathrm{mg}, n=10)$ crayfish biomass by round goby. Round goby consumed a mean of $285 \mathrm{mg}$ small crayfish juveniles (all 50) and $\sim 593.4 \mathrm{mg}$ of medium juvenile crayfish in $24 \mathrm{~h}$. They consumed fewer of the larger group, in average $43 \pm 6.48$ medium juveniles. The mean biomass of juvenile crayfish consumed was $45.7 \%$ of round goby wet weight.

\subsection{Competition for shelter}

\subsubsection{Experiment 4, daily observations of competition} for shelter over 8 days

We made 1225 observations. Round goby spent the majority of time in or near the shelter, while marbled crayfish took alternative shelter near the air stone or in the corner of the aquarium (Fig. 4). By day six, $40 \%$ of the crayfish had molted and were subsequently killed and partially eaten by round gobies. A single crayfish (weight: $130 \mathrm{mg} / \mathrm{TL}: 38 \mathrm{~mm}$ ) was observed (day two) to capture, kill, and consume a round goby (weight: $120 \mathrm{mg} / \mathrm{TL}: 50 \mathrm{~mm}$ ).

A GLM analysis with Poisson distribution (dispersion parameter set at 1) showed the number of observations at a given position to differ significantly $\left(\chi^{2}<806.89\right.$, $\mathrm{df}=5$, $p<0.001)$. Individuals were observed leaving positions between recorded time points. The number of observations at specific locations at 08:00, 11:00, 14:00, 17:00 $\mathrm{h}$ differed significantly $\left(\chi^{2}=17.36, \mathrm{df}=18, p<0.01\right)$ as well as the number of observations at the locations at 08:00, 11:00, 14:00, 17:00 h between species $\left(\chi^{2}<526.03, \mathrm{df}=6, p<0.001\right)$ (see Fig. 4).
Table 4. Mean time spent in shelter by round goby Neogobius melanostomus and marbled crayfish Procambarus virginalis during light and dark periods. The data analyzed by GLM with Gaussian distribution. Different superscripts indicate significant differences $(p<0.05)$ between species. Data are presented as mean \pm standard deviation.

\begin{tabular}{lll}
\hline Animal & Photoperiod & $\begin{array}{l}\text { Average time spent } \\
\text { in shelter (s) }\end{array}$ \\
\hline Round goby & Light & $15851 \pm 11420^{\mathrm{a}}$ \\
& Dark & $12378 \pm 13640^{\mathrm{a}}$ \\
Marbled crayfish & Light & $22365 \pm 18435^{\mathrm{b}}$ \\
& Dark & $15723 \pm 11114^{\mathrm{a}}$ \\
\hline
\end{tabular}

\subsubsection{Experiment 5, twenty-four-hour observation of competition for shelter}

Individuals of both species were always observed to leave the occupied shelter when a specimen of the other species entered. Crayfish pursued goby with open chelae, one capture was observed during the experiment.

We found a significant difference between species in the use of shelter during light and dark periods $(t=0.51, p<0.05)$, as the species alternated in shelter occupancy (Tab. 4). Marbled crayfish spent more time in shelters during light hours. Using GLM analysis, we found a significantly greater number of attacks during the light period than during the dark period by both species $(t=1.78, p<0.05)$ (Tab. 5), with round goby 
Table 5. The total number and percentage of attacks observed by round goby Neogobius melanostomus and marbled crayfish Procambarus virginalis during light and dark periods and the total time spent (s) in aggressive behavior. The data analyzed by GLM with Gaussian distribution. Different superscripts indicate significant differences $(p<0.05)$.

\begin{tabular}{llll}
\hline Animal & Photoperiod & $\begin{array}{l}\text { Number of } \\
\text { attacks (\%) }\end{array}$ & $\begin{array}{l}\text { Duration of } \\
\text { attacks (s) }\end{array}$ \\
\hline \multirow{3}{*}{ Round goby } & Light & $237(60.61)$ & $2140^{\mathrm{b}}$ \\
& Dark & $127(54.04)$ & $324^{\mathrm{a}}$ \\
Marbled crayfish & Light & $154(39.39)$ & $926^{\mathrm{b}}$ \\
& Dark & $108(45.96)$ & $274^{\mathrm{a}}$ \\
\hline
\end{tabular}

showing higher aggression. Round goby attacked crayfish more during day, while it was less active during night but still performing attacks more than crayfish (Tab. 5).

\section{Discussion}

Round goby has colonized major European river systems and coastal waters as well as North American freshwater ecosystems and has the potential to cause ecological regime shifts (Borcherding et al., 2011; Hempel and Thiel, 2013; Roche et al., 2015). Many European lake and stream communities also harbor non-native crayfish species that have considerable impact on native species, such as the signal crayfish Pacifastacus leniusculus (Dana, 1852), the spiny cheek crayfish Faxonius limosus (Rafinesque, 1817), and, relatively recently, the marbled crayfish $P$. virginalis (Kouba et al., 2014; Kubec et al., 2019). We focused on interaction of round goby, recently spread to upper stretches of the River Elbe (Roche et al., 2015; Buřič et al., 2015), with marbled crayfish as a model species representing the North American crayfish family Cambaridae (Hossain et al., 2019).

Round goby usually preys upon small bottom-dwelling vertebrates and invertebrates (Mikl et al., 2017), but is adaptable to feeding on a wide array of available prey types, including scavenging of carcasses, and particle sizes (Polačik et al., 2009, 2015; Perello et al., 2015). Crustaceans and mollusks represent the most important food items (Brandner et al., 2013). Crayfish can serve as an important food source for predatory fish, as demonstrated by a study of marbled crayfish (Lipták et al., 2019). Due to the results of experiment 1, it is hard to interpret if round goby was size-selective or not, but mouth gape and total length were significant limiting factors for consumption of larger crayfish class. Gobies were able to swallow all small and medium crayfish, but also to kill and partially consume the larger prey as larger crayfish were rather too big for smaller goby individuals. Non-selectivity of round goby was confirmed with mussels as prey (Perello et al., 2015). Ray and Corkum (1997) observed that round gobies spit out the entire mussel shell as well as pieces, similar to our observations of crayfish cuticula in aquaria. Higher temperature induced higher consumption of marbled crayfish (especially medium size class) by round goby. The positive temperature effect on round goby food consumption confirmed results of Lee and Johnson (2005) who showed increased consumption to $23-26^{\circ} \mathrm{C}$. But, results of experiment 2 suggest an interaction in proportion of marbled crayfish consumed between medium and large crayfish size with increasing mouth gape (Fig. 3) at $17^{\circ} \mathrm{C}$ but not at $21^{\circ} \mathrm{C}$. This indicates that larger gobies might prefer larger prey at lower temperatures while showing no preference at higher temperatures. As the consumption of larger prey items is more energy-efficient (Sih, 1980), this feeding behavior might be advantageous especially at low temperatures because energy loss is more important for a predator (Rall et al., 2010). In contrast, in exp. 1. bigger crayfish were less consumed but here no free prey size selection was possible as we used pairs of single goby and single crayfish and crayfish were randomly put in aquarium, thus it could be that smaller gobies were combined with bigger crayfish and could not predate on them. Round goby was able to consume a large number of crayfish at higher temperatures without showing signs of size-selectivity. This is contrary to crayfish size selection of smallmouth bass Micropterus dolomieu (Lacépède, 1802), which chose the smallest crayfish Faxonius propinquus (Girard, 1852) first and then consumed animals in ascending order of size (Stein, 1977), but also noted by other predatory fishes. All in all, round goby in our study consumed from 200 to $500 \mathrm{mg}$ of crayfish biomass per day, which was almost half of their own weight.

Generally, crayfish species share habitats with small bottom-dwelling fish species, such as darters (Mayden et al., 1992) and gobies (Church et al., 2017). Benthic fish can affect crayfish abundance through predation, and crayfish may compete with them for food resources (Thomas and Taylor, 2013). Benthic fish and crayfish naturally overlap in habitat use, with both primarily utilizing natural shelter beneath stones (Kubec et al., 2019), and exhibit a strong temporal overlap in their requirement for shelter (Cooper et al., 2009). In addition, both tested species are mainly nocturnal (Savino et al., 2007; Kornis et al., 2012; Kubec et al., 2019), and competition for shelter is likely to be strongest during the daylight hours (Hill and Lodge, 1994). Despite the fact that round gobies feed more during daylight hours, nocturnal feeding is facilitated by well-developed sensory systems enabling rapid and precise localization and capture of prey (Jude, 1997). With the adaptability to utilize food sources and space upon which crayfish depend (Kornis et al., 2012, 2013), it can be a strong competitor.

The previously reported decreased shelter occupancy by round goby during the night (Dubs and Corkum, 1996; Savino et al., 2007) was confirmed in our study. Crayfish, which show highest activity at dusk and during the night, were also reported to seek shelter during daylight (Bubb et al., 2009). An experiment confronting non-native signal crayfish with bottom-dwelling European bullhead Cottus gobio (Linnaeus, 1758), resulted in reduced shelter use by the fish (Bubb et al., 2009). However, our results from the experiment 4 with daily observations showed that round goby spent more time in shelters than marbled crayfish, which used alternative hiding places. Round goby and marbled crayfish spent roughly equal amounts of time in the shelter as well as equal time in avoidance. This could be the result of avoidance after dominance establishment subsequent to aggressive interactions, as well as the dominant status of round goby, as crayfish 
remained outside shelter more than expected. Bilateral avoidance confirms reciprocal alteration of behavior of the tested species.

Due to the results of experiment 5, observations of aggressive encounters showed that crayfish were usually able to resist round goby attacks, except after molting. Their size itself was not an obstacle to consumption by round goby as long as the carapax was intact. Following molt, even a large crayfish can be extremely vulnerable to predation (Stein, 1977), and it is reported that small crayfish in particular may be vulnerable to predation by round goby when they are softshelled immediately following a molt (Ray and Corkum, 1997). Our results showed that even crayfish of similar weight to the fish could be preyed upon by round goby after molting, which is remarkable when the mouth gape size of round goby is taken into account.

Both species showed intense aggressive behavior in experiment 5 . Round goby displayed more aggressive behavior than crayfish in our study, as reported by Church et al. (2017), but we observed a single instance of a crayfish attacking, killing, and feeding on a round goby. Round goby can hide in the sand and attack crayfish from behind, but were more likely to occupy shelters also used by crayfish. Round goby presence altered the shelter use by crayfish, but round goby behavior is also affected by crayfish presence, demonstrating a mutual interaction of two unrelated invasive species that occupy similar habitats.

Further investigation is necessary to elucidate interactions of round goby and larger crayfish in more complex conditions, as well as to estimate an effect on crayfish population structure. Altered behavior in both species can lead to higher vulnerability to predators (Blake and Hart, 1993; Kubec et al., 2019). Competition for resources can induce increased pressure on resources and accelerate migration to habitats with lower pressure as well as to shifts in ecological niche (Gherardi, 2007). Findings of this study can be useful in the management and conservation of the native North American Cambarid species, but also round goby could exert a control on other species juvenile crayfishes, so eradication of round goby would be considered.

As many other factors are responsible for invader success in natural conditions (Gebauer et al., 2018), the present study provides a baseline for ongoing study of particular scenarios and factors that influence the success and spread of alien aquatic organisms. Our results are in accordance with the known predatory capability of round goby and broaden it from the point of interactions with crayfish representative. Early juvenile crayfish are most vulnerable due to round goby predation. Round goby can possibly cause considerable declines in invasive crayfish species of genus Cambaridae in Europe. Naturally, they can have similar effects on other cambarid species in their native range in North American freshwaters. Hence our results can be easily transferred also to localities in North America inhabited by round goby.

\section{Supplementary Material}

Figure S1. The simple linear relationship between round goby mouth gape and round goby total length were undertaken using the default $\mathrm{lm}$ function in the $\mathrm{R}$ statistical program ( $\mathrm{R}$ Core Team, 2020). Correlations which had an adjusted $R^{2}>0.5$ and $p<0.05$ were considered to represent significant relationship. Significant relationships between mouth gape and total length would represent a potential confounding factor in further analysis.

Figure S2. Tools used for mouth gape measurement.

The Supplementary Material is available at https://www.kmaejournal.org/10.1051/kmae/2021019/olm.

Acknowledgements. The study was financially supported by the Ministry of Education, Youth and Sports of the Czech Republic CENAKVA No. LM2018099 and the project MoBiaqua: Cross border monitoring of biological invasions as a tool for freshwater biodiversity conservation (project number 100314623, program of cross-border cooperation with Free State of Saxony; Hallo Nachbar, Ahoj Sousede, Interreg VA/2014-2020). The authors extend special thanks to Dr. Bořek Drozd for his invaluable assistance in conducting the field survey with capture of round gobies and to Dr. Jan Kubec for technical support in installation of the camera systems. We also deeply appreciate the assistance of Lucidus Consultancy for manuscript language correction.

\section{References}

Andriantsoa R, Tönges S, Panteleit J, Theissinger K, Carneiro VC, Rasamy J, Lyko F. 2019. Ecological plasticity and commercial impact of invasive marbled crayfish populations in Madagascar. BMC Ecol 19: 1-10.

Blake MA, Hart PJB. 1993. The behavioural responses of juvenile signal crayfish Pacifastacus leniusculus to stimuli from perch and eels. Freshw Biol 29: 89-97.

Bond WJ. 1994. Keystone species. In: Biodiversity and ecosystem function. Springer Berlin Heidelberg, Berlin, Heidelberg, pp 237-253.

Borcherding J, Staas S, Krüger S, Ondračková M, Šlapanský L, Jurajda P. 2011. Non-native Gobiid species in the lower River Rhine (Germany): recent range extensions and densities. $J$ Appl Ichthyol 27: 153-155.

Brandner J, Auerswald K, Cerwenka AF, Schliewen UK, Geist J. 2013. Comparative feeding ecology of invasive Ponto-Caspian gobies. Hydrobiologia 703: 113-131.

Bubb DH, O’Malley OJ, Gooderham AC, Lucas MC. 2009. Relative impacts of native and non-native crayfish on shelter use by an indigenous benthic fish. Aquat Conserv Mar Freshw Ecosyst 19: $448-455$.

Buřič M, Bláha M, Kouba A, Drozd B. 2015. Upstream expansion of round goby (Neogobius melanostomus) - first record in the upper reaches of the Elbe river. Knowl Manag Aquat Ecosyst 416: 32.

Chucholl C, Pfeiffer M. 2010. First evidence for an established Marmorkrebs (Decapoda, Astacida, Cambaridae) population in Southwestern Germany, in syntopic occurrence with Orconectes limosus (Rafinesque, 1817). Aquat Invasions 5: 405-412.

Church K, Iacarella JC, Ricciardi A. 2017. Aggressive interactions between two invasive species: the round goby (Neogobius melanostomus) and the spinycheek crayfish (Orconectes limosus). Biol Invasions 19: 425-441. 
Cooper MJ, Ruetz III CR, Uzarski DG, Shafer BM. 2009. Habitat use and diet of the round goby (Neogobius melanostomus) in coastal areas of Lake Michigan and Lake Huron. J Freshw Ecol 24: 477-488.

Copp GH, Bianco PG, Bogutskaya NG, Erös T, Falka I, Ferreira MT, Fox MG, Freyhof J, Gozlan RE, Grabowska J, Kováč V, MorenoAmich R, Naseka AM, Peňáz M, Povž M, Przybylski M, Robillard M, Russell IC, Stakenas S, Šumer S, Vila-Gispert A, Wiesner C. 2005. To be, or not to be, a non-native freshwater fish? $J$ Appl Ichthyol 21: 242-262.

Crandall KA, Buhay JE. 2007. Global diversity of crayfish (Astacidae, Cambaridae, and Parastacidae-Decapoda) in freshwater. Hydrobiologia 595: 295-301.

Degerman E, Nilsson PA, Nyström P, Nilsson E, Olsson K. 2007. Are fish populations in temperate streams affected by crayfish? A field survey and prospects. Environ Biol Fishes 78: 231-239.

Dorn NJ, Mittelbach GG. 1999. More than predator and prey: A review of interactions between fish and crayfish. Vie Milieu-Life Environ 49: 229-237.

Dubs DOL, Corkum LD. 1996. Behavioral interactions between round gobies (Neogobius melanostomus) and mottled sculpins (Cottus bairdi). J Great Lakes Res 22: 838-844.

Gebauer R, Divíšek J, Buřič M, Večeřa M, Kouba A, Drozd B. 2018. Distribution of alien animal species richness in the Czech Republic. Ecol Evol 8: 4455-4464.

Gebauer R, Veselý L, Vanina T, Buřič M, Kouba A, Drozd B. 2019. Prediction of ecological impact of two alien gobiids in habitat structures of differing complexity. Can J Fish Aquat Sci 76: 1954-1961.

Gherardi F. 2007. Biological invasions in inland waters: an overview. In: Gherardi F, ed. Biological invaders in inland waters: profiles, distribution, and threats. Invading nature: Springer series in invasion ecology. Springer, Dordrecht, pp 3-25.

Grabowska J, Pietraszewski D, Ondračková M. 2008. Tubenose goby Proterorhinus marmoratus (Pallas, 1814) has joined three other Ponto-Caspian gobies in the Vistula River (Poland). Aquat Invasions 3: 261-265.

Hempel M, Thiel R. 2013. First records of the round goby Neogobius melanostomus (Pallas, 1814) in the Elbe River, Germany. BioInvasions Rec 2: 291-295.

Hill AM, Lodge DM. 1994. Diel changes in resource demand: competition and predation in species replacement among crayfishes. Ecology 75: 2118-2126.

Hossain MS, Kouba A, Buřič M. 2019. Morphometry, size at maturity, and fecundity of marbled crayfish (Procambarus virginalis). Zool Anz 281: 68-75.

Hossain MS, Patoka J, Kouba A, Buřič M. 2018. Clonal crayfish as biological model: a review on marbled crayfish. Biologia 73 : 841-855.

Jude DJ. 1997. Round gobies: cyberfish of the third millennium. Gt Lakes Res Rev 3: 27-34.

Kessel NV, Dorenbosch M, Spikmans F. 2009. First record of Pontian monkey goby, Neogobius fluviatilis (Pallas, 1814), in the Dutch Rhine. Aquat Invasions 4: 421-424.

Kornis MS, Mercado-Silva N, Vander Zanden MJ. 2012. Twenty years of invasion: a review of round goby Neogobius melanostomus biology, spread and ecological implications. J Fish Biol 80: 235-285.

Kornis MS, Sharma S, Jake Vander Zanden M. 2013. Invasion success and impact of an invasive fish, round goby, in Great Lakes tributaries. Divers Distrib 19: 184-198.
Kouba A, Petrusek A, Kozák P. 2014. Continental-wide distribution of crayfish species in Europe: update and maps. Knowl Manag Aquat Ecosyst 413: 05.

Kubec J, Kouba A, Buřič M. 2019. Communication, behaviour, and decision making in crayfish: a review. Zool Anz 278: 28-37.

Lee VA, Johnson TB. 2005. Development of a bioenergetics model for the round goby (Neogobius melanostomus). $J$ Great Lakes Res 31: $125-134$.

Lipták B, Mrugała A, Pekárik L, Mutkovič A, Grul'a D, Petrusek A, Kouba A. 2016. Expansion of the marbled crayfish in Slovakia: beginning of an invasion in the Danube catchment? J Limnol 75: 305-312.

Lipták B, Veselý L, Ercoli F, Bláha M, Buřič M, Ruokonen TJ, Kouba A. 2019. Trophic role of marbled crayfish in a lentic freshwater ecosystem. Aquat Invasions 14: 299-309.

Mayden R, Page L, Burr B. 1992. A field guide to freshwater fishes of North America North of Mexico. Copeia 920-925.

Mikl L, Adámek Z, Všetičková L, Janáč M, Roche K, Šlapanský L, Jurajda P. 2017. Response of benthic macroinvertebrate assemblages to round (Neogobius melanostomus, Pallas 1814) and tubenose (Proterorhinus semilunaris, Heckel 1837) goby predation pressure. Hydrobiologia 785: 219-232.

Patoka J, Buřič M, Kolář V, Bláha M, Petrtýl M, Franta P, Tropek R, Kalous L, Petrusek A, Kouba A. 2016. Predictions of marbled crayfish establishment in conurbations fulfilled: evidences from the Czech Republic. Biologia 71: 1380-1385.

Perello MM, Simon TP, Thompson HA, Kane DD. 2015. Feeding ecology of the invasive round goby, Neogobius melanostomus (Pallas, 1814), based on laboratory size preference and field diet in different habitats in the western basin of Lake Erie. Aquat Invasions 10: 463-474.

Polačik M, Janáč M, Jurajda P, Adámek Z, Ondračková M, Trichkova T, Vassilev M. 2009. Invasive gobies in the Danube: invasion success facilitated by availability and selection of superior food resources. Ecol Freshw Fish 18: 640-649.

Polačik M, Jurajda P, Blažek R, Janáč M. 2015. Carcass feeding as a cryptic foraging mode in round goby Neogobius melanostomus. J Fish Biol 87: 194-199.

Ray WJ, Corkum LD. 1997. Predation of zebra mussels by round gobies, Neogobius melanostomus. Environ Biol Fishes 50: 267-273.

Reynolds JD. 2011. A review of ecological interactions between crayfish and fish, indigenous and introduced. Knowl Manag Aquat Ecosyst 401: 10.

Roche K, Janáč M, Šlapanský L, Mikl L, Kopeček L, Jurajda P. 2015. A newly established round goby (Neogobius melanostomus) population in the upper stretch of the river Elbe. Knowl Manag Aquat Ecosyst 416: 33.

Savino JF, Riley SC, Holuszko MJ. 2007. Activity, aggression, and habitat use of ruffe (Gymnocephalus cernuus) and round goby (Apollonia melanostoma) under laboratory conditions. J Great Lakes Res 33: 326-334.

Sih A. 1980. Optimal foraging: partial consumption of prey. The American Naturalist 116: 281-290.

Stein RA. 1977. Selective predation, optimal foraging, and the predator-prey interaction between fish and crayfish. Ecology 58: $1237-1253$

Thomas CL, Taylor CA. 2013. Scavenger or predator? Examining a potential predator-prey relationship between crayfish and benthic fish in stream food webs. Freshw Sci 32: 1309-1317. 
S. Roje et al:: Knowl. Manag. Aquat. Ecosyst. 2021, 422, 18

Vanderploeg HA, Nalepa TF, Jude DJ, Mills EL, Holeck KT, Liebig JR, Grigorovich IA, Ojaveer H. 2002. Dispersal and emerging ecological impacts of Ponto-Caspian species in the Laurentian Great Lakes. Can J Fish Aquat Sci 59: 1209-1228.
Verliin A, Kesler M, Svirgsden R, Taal I, Saks L, Rohtla M, Hubel K, Eschbaum R, Vetemaa M, Saat T. 2017. Invasion of round goby to the temperate salmonid streams in the Baltic Sea. Ichthyol Res 64 $155-158$.

Cite this article as: Roje S, Richter L, Worischka S, Let M, Veselý L, Buřič M. 2021. Round goby versus marbled crayfish: alien invasive predators and competitors. Knowl. Manag. Aquat. Ecosyst., 422, 18. 